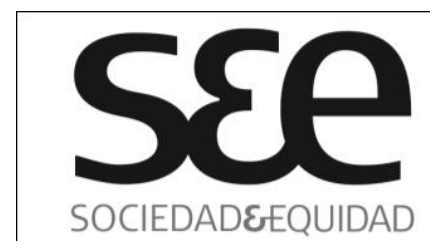

\section{Derechos Humanos y Derecho a la alimentación en situaciones de pobreza: El caso de Barrio Sur, Tucumán, Argentina}

Human Rights and the right to alimentation in situations of poverty: the case of Barrio Sur, Tucumán in Argentina

$\begin{array}{ll}\text { Nombre: } & \text { Griselda Alfaro }{ }^{(1)} \\ \text { Filiación: } & \text { Universidad Nacional de Tucumán } \\ \text { País: } & \text { Argentina } \\ \text { Correo: } & \text { gryalfaro@yahoo.com.ar }\end{array}$

\title{
Resumen
}

Este trabajo tuvo por objetivo analizar las formas de vida y la problemática del derecho a la alimentación en situaciones de pobreza e indigencia en hogares del Barrio Sur de la localidad de Juan Bautista Alberdi. Por un lado, quisimos llamar la atención sobre la insatisfacción de las necesidades individuales y colectivas del binomio alimentación-nutrición en los miembros del Barrio Sur, lugar donde evidenciamos la disociación entre la norma y la práctica como obstáculo para revertir el problema del hambre. Por otro lado, quisimos recoger la voz de los sujetos de derechos a través de entrevistas semi-estructuradas $\mathrm{y}$, al hacerlo, identificar y construir nuevas formas, más humanas, pero académicamente rigurosas, para poner el tema de los derechos humanos, y su exigibilidad al servicio de la ciudadanía.

\section{Palabras Claves}

Derechos Humanos, Derecho a una alimentación adecuada, Pobreza, Ciudadanía, Hambre, Políticas Públicas.

\footnotetext{
${ }^{1}$ La autora es Doctora en Humanidades, área Derecho. Sus líneas de investigación son los Derechos Humanos.
} 


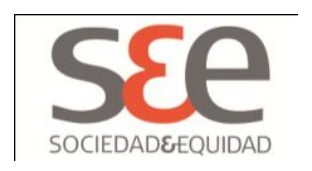

\begin{abstract}
This study analyzes the ways of life and the problems concerning the right to food in situations of poverty and indigence in the homes of "Barrio Sur" in Juan Bautista Alberdi, Argentina. On the one hand, we wanted to draw attention to the lack of satisfaction of the individual and collective needs of the food-/nutrition binomial of the inhabitants of "Barrio Sur." We focus on the dissociation between policy and practice as an obstacle to reverse the problem of hunger. On the other hand, we wanted to collect the voice of the subjects of rights through semi-structured interviews in order to identify and build a more humane and academically accurate way to place the topic of human rights, and their enforceability at the service of the citizens.
\end{abstract}

\title{
Keywords
}

Human Rights, Right to Food, Poverty, Citizenship, Hunger, and Public Policies.

\section{Introducción}

Históricamente, la noción de derechos humanos estuvo relacionada con la afirmación de la dignidad de la persona frente al Estado, es decir, pensar el poder público al servicio del ser humano.

En este sentido, la sociedad contemporánea y, en especial, la comunidad internacional organizada reconoció que todo ser humano, por el solo hecho de serlo, tiene derechos frente al Estado que no pueden ser renunciados o transgredidos.

La formulación de dicha aseveración fue un proceso de tiempo prolongado porque fue con posterioridad a la Segunda Guerra Mundial que surgió el sistema internacional de protección de los derechos humanos con la creación de la Organización de Naciones Unidas en 1945 y la Declaración Universal de los Derechos Humanos adoptada en el año 1948. Esta declaración incluyó los derechos económicos, sociales y culturales, y los derechos civiles y políticos. Aún así, los Estados complementaron la Declaración Universal con dos tratados específicos, el Pacto Internacional de Derechos Civiles y Políticos (PIDCP), reconociendo dichos derechos como de primera generación (libertad de expresión, derecho a la vida) y el Pacto Internacional de Derechos Económicos, Sociales y Culturales (PIDESC) 


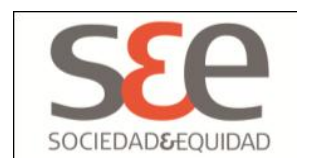

registrando derechos de segunda generación como vivienda, alimentación o educación.

En consecuencia, la aprobación de los dos Pactos colaboró en la adopción de una posición conservadora que categorizó a los DESC como normas no exigibles a través de reclamos ante los organismos judiciales. Es decir, dicho pensamiento los redujo, en su momento, a meros actos políticos o hechos morales desvinculados de su naturaleza de normas jurídicas vinculantes.

El salto cualitativo superador de la dicotomía entre DESC y DCP comenzó a sobresalir cuando la doctrina y los actores del Sistema Interamericano de Derechos Humanos como Víctor Abramovich y Christian Courtis entre otros, aportaron elementos para consolidar la exigibilidad de los DESC:

"Si bien puede concederse que existen limitaciones a la justiciabilidad de los Derechos Económicos Sociales y Culturales cabe concluir en el sentido inverso: dada su compleja estructura, no existe Derecho Económico, Social o Cultural que no presente al menos alguna característica o faceta que permita su exigibilidad en caso de violación" (Abramovich, Courtis, 2004: 91).

En el plano nacional, nuestra Carta Magna fue reformada en el año 1994 e incorporó, con jerarquía constitucional, una serie de Tratados Internacionales de Derechos Humanos, entre ellos, el aludido PIDESC. A nivel local, ya en el año 1995 la provincia de Tucumán reconoció como norma interna las disposiciones de la Convención Americana sobre Derechos Humanos, el Pacto Internacional de Derechos Económicos, Sociales y Culturales y el Pacto Internacional de Derechos Civiles y Políticos. En otras palabras, al incorporar a la normativa nacional y provincial los tratados internacionales, reconocieron voluntariamente la incorporación del enfoque basado en los derechos humanos, con la corresponsalidad de observar y hacer observar los derechos, las obligaciones y garantías consagradas y diseñar sus políticas públicas conforme dichos lineamientos.

Como marco conceptual para este trabajo adoptamos la noción del enfoque basado en los derechos humanos entendida de la siguiente manera:

"Es un marco conceptual para el proceso de desarrollo humano que desde el punto de vista normativo está basado en las normas internacionales de derechos humanos y desde el punto de vista operacional está orientado a la promoción y la protección de los derechos humanos. Su propósito es analizar las desigualdades que se encuentran en el centro de los problemas de desarrollo y corregir las 


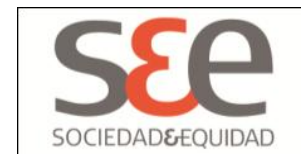

prácticas discriminatorias y el injusto reparto del poder que obstaculizan el progreso en materia de desarrollo"”.

Este marco general de los derechos humanos dio paso a la construcción de nuestro objeto de análisis: el derecho a una alimentación adecuada. La prerrogativa que analizamos fue reconocida de manera expresa por el PIDESC en su artículo $\mathrm{n}^{\circ} 11$ al observar que los Estados partes reconocen el derecho de toda persona a un nivel de vida adecuado para sí y su familia, incluso alimentación, vestido y vivienda adecuados, y a una mejora continua de las condiciones de existencia. Por su parte, el mismo artículo estableció que deberán adoptarse medidas inmediatas y urgentes para garantizar el derecho fundamental de toda persona a estar protegida contra el hambre. Este derecho significa que cada niño/a, hombre o mujer tengan acceso permanente a alimentos suficientes en cantidad y calidad nutricional, inocuos y culturalmente adecuados para quien los consume.

El carácter de adecuada tiene por propósito acentuar que el derecho a la alimentación no debe ser interpretado en sentido restringido como un cúmulo de calorías, por el contrario, el contenido del derecho fue conformado con los factores culturales, sociales, económicos y ecológicos como lo indicó la Observación General (OG) Nº 12.

En consecuencia en este trabajo se estudian diversos casos tales como las formas de vida y específicamente la problemática del derecho a la alimentación en situaciones de pobreza e indigencia en hogares del Barrio Sur de la localidad de Juan Bautista Alberdi. Por un lado, quisimos llamar la atención sobre la insatisfacción de las necesidades individuales y colectivas del binomio alimentación-nutrición en los miembros del Barrio Sur, lugar donde claramente evidenciamos la disociación entre la norma y la práctica como obstáculo para revertir el problema del hambre. Por otro lado, recogimos la voz de los sujetos de derechos y, al hacerlo, identificamos y construimos nuevas formas, más humanas, pero académicamente rigurosas, para poner el tema de los derechos humanos, su exigibilidad y justiciabilidad al servicio de la ciudadanía.

\footnotetext{
2 Oficina del Alto Comisionado de Derechos Humanos, (2006) "Preguntas frecuentes sobre el enfoque de derechos humanos en la cooperación para el desarrollo", Nueva York, Ginebra.
} 


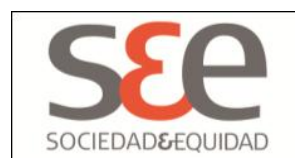

\section{Barrio Alberdi Sur- Asentamiento de orillas de la vía del tren}

La estrategia de recolección de datos provenientes del trabajo de campo requirió una revisión teórica previa. Cabe agregar que las visitas fueron acompañadas por un antropólogo y una trabajadora social. Entre la bibliografía revisada dos artículos por su relevancia para la elaboración del marco conceptual y metodológico.

El primer artículo, "Un abordaje de la fenomenología del hambre" de María do Carmo de Freitas (Do Carmo, 2002:54), explica que para abordar el concepto de "hambre" es esencial trabajarlo a partir de las propias experiencias y concepciones de las personas. Esta autora considera que el hambre es un fenómeno que cala al ser humano marcándolo de tal forma, aún en los momentos en que tiene que comer. "El hambre es un fenómeno que impregna al ser humano que vive o habita en precarias condiciones de vida, debido a las temporalidades, el cuerpo y la memoria, trasciende el evento económico y social de su ocurrencia"”.

Do Carmo destaca en su investigación que quienes sufren hambre muchas veces no advierten las secuelas físicas que tienen en sus cuerpos. Por ejemplo, no siempre se advierte el tema del peso corporal como un problema de salud. El hecho de ser gordo o delgado va más allá de una situación estética porque el hambre está presente en todo momento de la vida, como una herida de la existencia, independientemente del peso corporal de las personas.

El segundo texto, la tesis de José Raimundo Sousa Ribeiro Junior (Sousa, 2008:15), Alimentación y una crítica de la vida cotidiana a partir de la Geografía Urbana, es una investigación sobre la necesidad de la comprensión de la urbanización crítica para obtener un entendimiento de la alimentación y del hambre en las ciudades, zonas periurbanas y rurales. Para el cumplimiento de su objetivo el autor trabajó en lugares de la Ciudad de San Pablo, Brasil. Ribeiro sostiene: "La miseria de la vida cotidiana se manifiesta como una miseria en la alimentación que puede ser percibida en los diferentes estratos de la sociedad"4. Entre sus conclusiones el autor consideró que el hambre tiene el potencial de visibilizar la deshumanización del período en que vivimos.

Los enfoques antes mencionados permitieron la reconstrucción del contexto "socio-territorial" donde se reproduce la vida cotidiana de los sujetos y hogares

\footnotetext{
${ }^{3}$ Do Carmo de Freitas, María (2002); "Un abordaje fenomenológico del Hambre", en Revista Nutrición, Campinas, Enero-Abril.

${ }^{4}$ Raimundo Sousa Ribeiro Junior, José, (2008) Tesis inédita para el Título de Grado en Maestro de Geografía: "Alimentación y una crítica de la vida cotidiana a partir de la Geografía Urbana," Facultad de Filosofía, Letras y Ciencias Humanas, Universidad de San Pablo, Brasil. La traducción es propia.
} 


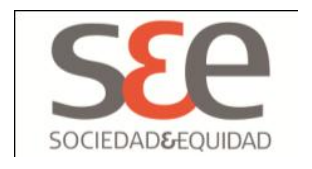

del Barrio Sur, es decir, de una comunidad que ilustró claramente las expresiones más crudas de la pobreza y la desigualdad social en Tucumán, Argentina.

La metodología utilizada fue la realización de entrevistas semiestructuradas en los hogares del Barrio Sur que tuvieran al menos un hijo o hija entre 0 y 18 años. Como resultará del desarrollo del presente trabajo, nuestro análisis está focalizado en la niñez. Para mayor organización de la información decidimos dividirla en boques:

Introductorio vinculado con las forma de vida, composición del grupo familiar, características habitacionales, educación y situación laboral. Luego, destinamos un bloque de preguntas específico destinado a la alimentación, es decir, cómo y dónde adquieren los alimentos, qué tipo de comidas ingieren, etc. Para el último bloque, nuestras preguntas estuvieron concentradas en una cuestión monetaria con el fin de conocer si el ingreso que perciben les permite vivir todo el mes y realizar la compra de los alimentos. Además, al final de cada jornada de trabajo, la información obtenida fue volcada en la libreta de campo, en un registro de las diferentes narraciones, eventos y los protagonistas que en forma directa o indirecta tuvieron relación con el tema de la investigación. Esto se hizo con la finalidad de definir la discusión en torno al problema del derecho a la alimentación adecuada en contextos de pobreza.

Asimismo, por razones de privacidad en las descripciones que realizaremos al analizar las entrevistas en Barrio Sur, no daremos a conocer el nombre real de las personas entrevistadas, para dar cuenta de sus relatos utilizaremos nombres ficticios y algunas frases relevantes para nuestro análisis serán expuestas textualmente con las palabras utilizadas por los/as entrevistados/as.

\section{Contexto Provincial}

San Miguel de Tucumán es la capital de la provincia más pequeña pero la más densamente poblada de la República Argentina. Se encuentra situada en la Región del Norte Argentino y sus límites son: al Norte con la provincia de Salta, al Este y Sur con la provincia de Santiago del Estero y al Oeste y Sur con la provincia de Catamarca. Se estima que posee una población de 1.448.200 habitantes, según valoraciones del Instituto Nacional de Estadísticas y Censos (INDEC) luego del Censo Nacional de Población del año $2010^{5}$.

La provincia está dividida en 17 departamentos entre los cuales se encuentra Juan Bautista Alberdi. Específicamente, está ubicado en el sudoeste de

\footnotetext{
${ }^{5}$ Consultado el día 10 de abril de 2011, Disponible en: http://www.indec.mecon.ar/
} 


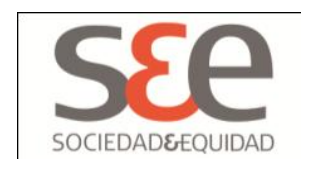

la provincia y limita al norte con el departamento Río Chico, al este con Graneros, al sur con el departamento La Cocha, y al oeste con la provincia de Catamarca. En Alberdi viven 30.095 habitantes de acuerdo con los datos del Censo Nacional de Población del año 2010.

En la actualidad los asentamientos periurbanos constituyen un fenómeno social que creció en los intentos de urbanización de la población de escasos recursos, como analizaremos en el caso de la población asentada a orillas de las vías del ferrocarril en Juan Bautista Alberdi. Esta población será identificada como centinela, que en palabras de Juan Samaja (Samaja, 200:13) es una unidad de estudio que representa características estructurales tipológicas y donde, a su vez, los pobladores comparten un territorio y una dinámica cultural significativa conformando un microcampo de información. Llamaremos a la población centinela Barrio Sur, lugar donde sus habitantes se dieron un nombre y otorgaron sentido a las expresiones de su vida cotidiana.

\section{Barrio Sur}

El Barrio Sur se encuentra en las afueras de la ciudad de Juan Bautista Alberdi y está construido a los costados de la vía del tren, que desde hace muchos años no circula más. Este hecho nos parece una clara evidencia de la situación de pobreza y abandono que se vive en la zona de estudio.

Barrio Sur colinda de un lado con plantaciones de tabaco o soja, según la época del año, y del otro lado con un canal de aguas servidas del ingenio.

Es un asentamiento precario en tierras fiscales por lo que ninguna de las personas que allí viven posee títulos que les otorguen la propiedad de las tierras. La mayor parte de las casas son de madera y chapa. Muy pocas están construidas con materiales firmes en su totalidad o en alguna de sus partes como dormitorios o cocina.

Los terrenos son pequeños y están divididos por alambre o cercos de madera. En el caso de los que limitan con el canal tienen unos muros de contención con chapas o varas de la caña de azúcar. La infraestructura es precaria, ya que no tienen cloacas, agua corriente, medidores de luz propia, ni calles entre las viviendas, sin embargo, ellos acceden a los servicios de forma inestable al unirse a otras redes.

Los habitantes del barrio conforman aproximadamente 50 familias, entendidas como unidades domésticas acorde a la unidad de análisis en los relevamientos del INDEC relativos a pobreza. Una importante fuente de ingresos de los pobladores es 


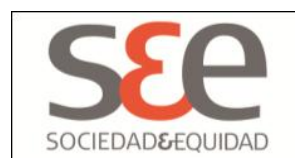

el trabajo en las cosechas. Para realizar las compras diarias o para asistir al hospital deben trasladarse hasta el centro de Alberdi, o algún otro barrio más cercano que cuente con una despensa o algún minimercado.

\section{Consideraciones en relación con las entrevistas realizadas}

Como expusimos al comienzo del artículo, el primer bloque de preguntas estuvo dirigido a las siguientes tipologías: forma de vida, composición del grupo familiar, características habitacionales, educación y situación laboral. Luego realizamos un bloque de preguntas específico destinado a la alimentación, cómo y dónde adquieren los alimentos: qué tipo de comidas ingieren y; cuántas veces al día comen; si sus hijos/as estuvieron o están bajos de peso, de acuerdo al diagnóstico médico; si reciben algún plan social; y si recibieron o reciben educación alimentaria para la manipulación de los alimentos, higiene en la cocina y modos de vida sanos, con la finalidad de prevenir tanto las enfermedades nutricionales originadas por el déficit en el consumo de energía o nutrientes específicos, como de las enfermedades crónicas no transmisibles relacionadas con la dieta.

Para la última etapa, nuestro cuestionario estuvo agrupado en torno a la cuestión monetaria con el objetivo de conocer si con el ingreso que perciben pueden realizar la compra de los alimentos para toda la quincena o el mes. La idea de este bloque fue establecer relaciones entre la compra y el consumo de los alimentos para advertir ciertas características sobre la alimentación de esta población.

\section{$1^{\circ}$ Bloque: Forma de Vida}

Las observaciones y las entrevistas realizadas, pusieron de manifiesto las características habitacionales del barrio que previamente mencionamos. En conjunto, se trataba de grupos numerosos de familias y estaban integrados por alrededor de cuatro personas como mínimo y doce como máximo. Otra característica a resaltar es que en todas las unidades domésticas había niños, niñas y adolescentes.

La mayoría de las casas estaban construidas con madera y chapa, solo cuatro o cinco de las casas visitadas eran de ladrillos. Sin embargo, todas tenían piso de tierra. Respecto del tamaño, destacamos que algunas eran pequeñas y contaban con una sola habitación en la que dormían hasta diez personas. Había otras casas un poco más amplias, que contaban con dos habitaciones.

La mayor parte de las casas no tenían baño y poseían una letrina que se encontraba al costado o al fondo de la casa. Por lo general, no tenían cocina y a un 


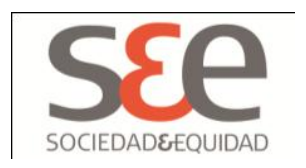

costado de la casa algunas tenían un horno de leña. En el caso de algunas familias, en la parte de atrás de la casa tenía una choza para hervir el agua y preparar sus alimentos. Otras, por el contrario, cocinaban, en una parrilla metálica y abajo colocaban las brasas para encender el fuego y así poder calentar los alimentos o hervir agua para lavar la ropa.

Respecto del interior de las casas, allí tenían las camas, algunos artefactos eléctricos como heladera, televisor, equipo de música o cocina a garrafa y en ese caso tenían la posibilidad de planificar y conservar los alimentos.

Los utensilios de cocina se limitaban a una o dos ollas, vasos y platos de plásticos o de aluminio, algunos cubiertos, un jarro para hervir agua.

En relación con la inserción social, consultamos por los aspectos educativos y laborales y podemos resaltar que la mayoría de los adultos explicaron que no habían concluido el ciclo educativo obligatorio, algunos/as de ellos/as sólo cursaron la primaria y otros pudieron realizar algunos años de secundaria.

En cuanto al ámbito laboral, la principal ocupación de la población adulta del barrio es la cosecha del citrus entre los meses de abril y septiembre. Esta actividad es realizada por la mayoría de los varones del barrio. Otros adultos se dedicaban a lo que denominan "hacer changuitas," entre las que destacamos actividades como panadería, albañilería, reparación de artefactos eléctricos, arreglos de bicicletas, cuidado de niños/as, lavado y planchado de ropa. Al no estar registrados en el sistema formal de trabajo, no tenían acceso a la seguridad social, vacaciones ni seguros de salud. En suma, todos estos empleos revisten el distintivo de precariedad. "El trabajo en el mercado informal apareció como algo seguro, ante la inseguridad de contratos laborales de corta duración que puede ofrecer el mercado formal"6.

Estas caracterizaciones permitieron coincidir con la afirmación planteada por Magdalena Reta, Graciela Rosi y Stella Maris Toler (Reta, Rosi y Toler, 2008:173) en el análisis de un barrio en Concordia, Entre Ríos, al sostener que "la lógica de las unidades de decisión es de sobrevivencia y no de acumulación". Sobrevivir o pasar el día, es lo que caracteriza el comportamiento de las familias entrevistadas, vivir al día. Las familias se encuentran emplazadas en terrenos de propiedad de terceros de forma ilegal, y desarrollan en ellos sus actividades productivas.

6 Reta Magdalena, Rossi Graciela y Toler Stella Maris, (2008) "La evaluación de las políticas alimentarias. Consideraciones metodológicas a partir del caso de la Ciudad de Concordia", Concordia: UNER. 


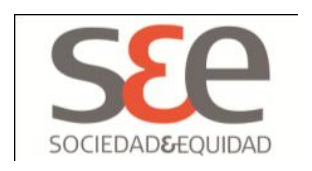

\section{$2^{\circ}$ Bloque: Alimentación}

Este bloque de preguntas referidas a la alimentación, tema central en nuestro análisis, tuvo por finalidad comparar la realidad que vivían las familias del barrio con los elementos del derecho a una alimentación adecuada conforme fueron definidos por el Comité de Derechos Económicos, Sociales y Culturales en la Observación General $N^{\circ}$ 12: disponibilidad, accesibilidad, adecuación y sostenibilidad.

A modo de introducción podemos decir que la alimentación en los hogares era común a todos los miembros de la familia. Era monótona y no existían dietas especiales para quienes estaban bajos de peso, dado porque la disponibilidad de dinero en los hogares y el precio de los alimentos, en aumento constante, impedía la satisfacción de requerimientos específicos para cada miembro en particular. El problema se agravaba cuando las familias eran numerosas porque, como indicaremos, el monto asignado en las tarjetas alimentarias actúa solo un complemento al salario general de la casa.

Así, las respuestas de los/ as entrevistados/as reveló que la mayoría no desayunaba o sólo tomaba mate cocido, algunos/as niños/as reciben el desayuno en la escuela. Los almuerzos o cenas eran a base de guisos, fideos, arroz, papas y algunas carnes o achuras. Algunos/as vecinos/as poseían pequeñas huertas por lo que accedían a verduras frescas, otros/as iban a las ferias que se realizaban los fines de semana y allí recogían las frutas y verduras que los/as puesteros/as desechaban por estar golpeadas o en mal estado, así acopiaban y seleccionaban lo que era posible recuperar para comer. Muchas familias del barrio comían en el comedor "Bichito de Luz" o buscaban allí la comida que llevaban para sus casas para comer en familia.

En consecuencia, la generalidad de los hogares visitados cocinaba al mediodía y a la noche recalentaban lo que había sobrado. En el caso de las familias que iban a almorzar al comedor Bichitos de Luz, ellas preparaban los alimentos para la cena o solamente tomaban mate cocido con pan, según la disponibilidad del momento.

Respecto de la leche, como un alimento necesario para los niños/as, las madres respondieron que la buscaban en el hospital o en los Centros de Atención Primaria de la Salud (CAPS) donde realizaban los controles de peso a los niños/as. Otro aspecto a destacar es que consumían jugos artificiales y gaseosas porque este tipo de bebidas se caracteriza por ser de alta densidad energética, aunque de muy bajo valor nutricional. Debido a que estas bebidas proveen gran cantidad de energía, eso hace que generen sensación de saciedad al consumirlas. No consumían 


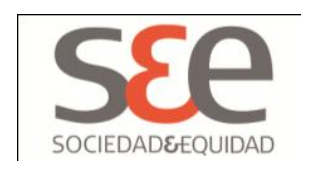

agua, por lo general, por la mala calidad del agua. A veces caminaban a las cercanías a buscar en los otros barrios para cargar bidones de agua potable y tener para cocinar o lavar.

Casi todos/as los/as entrevistados/as contaban con las tarjetas alimentarias del Programa Familia Crítica y Rehabilitación Nutricional, destinada a los/as niños/as diagnosticados/as con desnutrición. El monto mensual asignado a las tarjetas para la compra exclusiva de alimentos oscila entre los 50 y $70 \$$. Claro es que el mismo es insuficiente para todo el mes, sin embargo, para ellos/as, contar con dicha suma dineraria les permitía una mínima planificación y distribución de gastos, es decir, consideraban dicho ingreso como una cuota de accesibilidad a los alimentos.

Respecto de los recursos necesarios para la alimentación en los hogares, podemos decir que estaba formado por el salario que recibían de su trabajo formal o informal, fuera quincenal o mensual, apoyo social y alimentario a través de: la tarjeta alimentaria de los Programas Familia Críticas y/o Rehabilitación Nutricional, pensiones por discapacidad, pensión por mal de chagas, pensión a madres de siete hijos o más. También incluyeron entre sus recursos la ayuda de carácter privada o de la Iglesia Católica por medio de Cáritas, por ejemplo, y en algunos casos, como expusimos, la autoproducción de alimentos frescos.

Para la relación entre compra y consumo de alimentos (accesibilidad económica) destacamos que la respuesta de la mayoría de las personas entrevistas respondió que el principio rector es la búsqueda de los precios más accesibles para que la mercadería dure, es decir, no prima en las respuestas que la guía para la compra sea la calidad de los alimentos. Una vez más, quedó manifestado que el aumento del precio de los alimentos, los ingresos contingentes junto con la disminución de la capacidad de compra, les impedía adquirir alimentos que verificaban los estándares de cantidad, calidad y preferencia cultural.

Las entrevistadas respondieron que en el supermercado los precios eran más baratos, sin embargo, como debían caminar bastante y luego transportar la mercadería era difícil y preferían realizar las compras en los multiservicios cercanos al barrio, sobre todo en época de lluvia donde el camino se tornaba casi intransitable por el barro. 


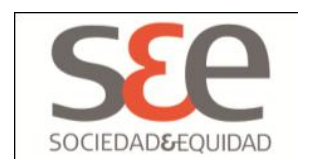

\section{Comedor Bichito de Luz}

El Comedor Bichito de Luz está ubicado aproximadamente a 500 metros del Barrio Sur. Durante la crisis Argentina que tuvo lugar en el año 2001-2002, el envío de los fondos para la compra de alimentos dependientes del Programa Social y Nutricional $^{7}$ (ProSoNu) estuvo retrasado y en consecuencia el comedor tuvo que cerrar sus puertas, lo que generó que muchas familias quedaran sin recibir su comida diaria, al no poder alimentarse en sus hogares por falta de trabajo y de ingresos insuficientes para hacer frente a la compra de provisiones. "El drama en cuestión impacta con mayor rigor en el Barrio Sur, de Alberdi. Allí viven cientos de familias en extrema pobreza. Se estima que un $15 \%$ de la población infantil está subalimentado".

Una vez restablecida la recepción de fondos, en la actualidad, este comedor brinda el almuerzo de lunes a viernes a recibir el almuerzo y los días lunes, miércoles y viernes también ofrecen la merienda a todos los que concurren.

Tuvimos la oportunidad de entrevistar a Marta, la encargada del lugar luego de finalizado el almuerzo para explicarnos cómo funcionaba el mismo.

El Comedor era para los/as niños/as del barrio y las cercanías. Sin embargo, brindaban alimentación a todas las personas que llegaban, es decir, incluían a los adultos también. Durante nuestra visita, vimos almorzar a madres con sus hijos/as, adultos mayores, pero nos sorprendió no ver hombres. Ante esta situación la Sra. Marta respondió:

“Muy pocos hombres llegan acá. Para ellos no poder alimentar a su familia es motivo de vergüenza y no quieren venir. Entonces lo que hacemos es darles la vianda para que sus esposas o hijos se las lleven a casa. Otra

\footnotetext{
7 En la década del 1980, el programa mencionado recibió el nuevo nombre de Promoción Social Nutricional (PROSONU) y hasta inicios de la década del 1990, el Programa era financiado y administrado por el Gobierno Nacional, bajo dependencia del entonces Ministerio de Salud y Acción Social. Este establecía convenios con cada provincia en los que se estipulaban los compromisos de cada parte, las metas y características de la alimentación a suministrar (provisión de 750 calorías diarias a los niños en edad escolar) y los montos que se transferirían a cada jurisdicción según los cupos establecidos. El programa tenía por finalidad disminuir las condiciones deficitarias de la alimentación de los escolares, contribuyendo al aumento del rendimiento escolar y a la disminución del ausentismo. Operativamente, cada provincia recibía los fondos transferidos por el Gobierno Nacional y los distribuía a cada escuela para la administración de desayunos o copas de leche, almuerzos y refrigerios.
} 


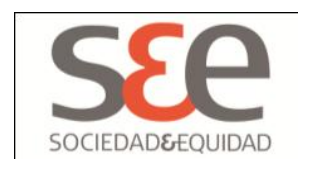

alternativa es que lleven la porción de cada uno y puedan comer en familia, el problema es que en algunas casas no tienen ni mesa".

El relato de Marta coincidió con Patricia Aguirre (Aguirre, 2005: 123) cuando en su libro Estrategias de Consumo señaló:

El impacto del comedor respecto de los varones, cuando no fue en el rol de organizadores, también fue demoledor. Por un lado cuestión su papel tradicional como proveedores, aunque este cuestionamiento durante la década cada vez fue más atenuado porque a medida que la desocupación se hacía masiva esto les permitía reconstruir positivamente su identidad como no-trabajadores-involuntarios, pasando de ser pobres a desocupados. Sin embargo, si mandar a los hijos al comedor (siempre que no fuera el comedor de la escuela, cuyas prestaciones se suponen universales y por lo tanto no acarrean la estigmatización para los concurrentes) suponía un padre que no cumple como padre, ir a un comedor se leía como pedir, lo que en términos de prestigio social era caer muy bajo y desde el punto de vista subjetivo significaba un quiebre personal, no poderse alimentar por sí mismo se leyó como un fracaso personal; como una valor negativo antes que un derecho conculcado.

Respecto de los fondos que recibían, Marta mencionó que provenían del Ministerio de Desarrollo Social de la Nación. Entre sus comentarios podemos destacar que: "Tomando en consideración los obstáculos ocurridos con la crisis, en el presente realizamos las compras por mayor de los alimentos no perecederos para armar un stock que permita tener una reserva para cuando la recepción de los fondos se atrase". Año a año se trabaja para optimizarlo en infraestructura e higiene, comentó Marta. Trabajamos en conjunto con una nutricionista que elaboraba los menús diarios para que la comida fuera variada y cumpliera con los estándares de calidad, suficiencia, respeto cultural. 


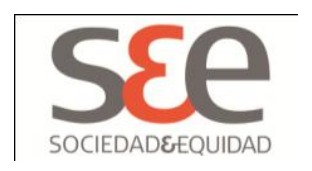

\section{El camino hacia una ciudadanía plena}

En este apartado realizaremos un breve recorrido por los estándares internacionales de Derechos Humanos del Sistema Interamericano para cotejarlos con la experiencia de los habitantes del Barrio Sur.

Al respecto, es pertinente mencionar la jurisprudencia establecida por la Corte Interamericana de Derechos Humanos en el caso Villagrán Morales y otros conocido como Niños de las Calle contra Guatemala del año 1999 donde fue expresado que la misión del artículo $n^{\circ} 19$ de la Convención Americana sobre Derechos Humanos $^{8}$ fue proteger la vulnerabilidad de los niños/as en su incapacidad para asegurar por sí mismos el respeto de sus derechos como sujetos plenos de derechos. Igualmente, afirmó que mientras que las consecuentes responsabilidades de protección corresponden en principio a la familia, en el caso de niños/as en riesgo se requieren medidas que emanen del Estado. Según la Comisión, este deber estatal especial abarcaba el amparo de una amplia gama de intereses, sociales, económicos, civiles y políticos, del niño.

En la misma sentencia, del voto concurrente conjunto de los Jueces Antonio Augusto CançadoTrindade y Alirio Abreu Burelli (1999), surgió que:

El deber del Estado de tomar medidas positivas se acentúa precisamente en relación con la protección de la vida de personas vulnerables e indefensas, en situación de riesgo, como son los niños en la calle. La privación arbitraria de la vida no se limita, pues, al ilícito de homicidio; se extiende igualmente a la privación del derecho de vivir con dignidad. Esta visión conceptualizó el derecho a la vida como perteneciente, al mismo tiempo, al dominio de los derechos civiles y políticos, así como al de los derechos económicos, sociales y culturales, ilustrando así la interrelación e indivisibilidad de todos los derechos humanos ${ }^{9}$.

Recordamos que los estándares aquí mencionados son vinculantes para los poderes del Estado en tanto son obligaciones cuyo incumplimiento compromete la responsabilidad internacional del nuestro país y el antecedente mencionado debe aplicarse al caso argentino en el diseño, implementación y monitoreo de las

\footnotetext{
8 Convención Americana sobre Derechos Humanos, suscripta en la Conferencia Especializada Interamericana sobre Derechos Humanos, San José, Costa Rica 7 al 22 de noviembre de 1969. Artículo $\mathrm{N}^{\circ}$ 19: Derechos del Niño. Todo niño tiene derecho a las medidas de protección que su condición de menor requieren por parte de su familia, de la sociedad y del Estado.

${ }^{9}$ Corte Interamericana de Derechos Humanos. Caso de los "Niños de la Calle" (Villagrán Morales y otros) Vs. Guatemala. Sentencia de 19 de noviembre 1999.
} 


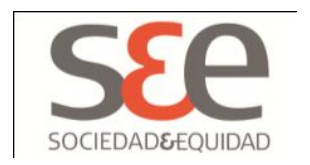

políticas públicas en materia de alimentación y niñez dada la unidad de los derechos humanos.

Ahora bien, una vez indicados los estándares internacionales de derechos humanos, debemos subrayar que disociación existente entre teoría y práctica porque la situación de vulnerabilidad en que se encontraban las familias, jóvenes, niños y niñas que habitan en el Barrio Sur es manifiesta cuando combinamos las entrevistas realizadas, los datos demográficos y las observaciones etnográficas.

En consecuencia, conforme lo detallado, los miembros de dicha comunidad en la práctica pueden ser incluidos en la categoría acuñada por Guillermo O'Donnell (O' Donnell, 1993: 62-87): ciudadanía de baja intensidad. Esta caracterización se refiere a una situación de carencia de la ciudadanía, en condiciones de pobreza, alto grado de desigualdad y la existencia de numerosos grupos para quienes la ciudadanía no está defendida ni definida. Esta categoría implicó el reconocimiento en un sentido formal de los derechos y garantías reconocidas por la Constitución y los Tratados Internacionales que correspondían a todos los habitantes de un Estado-Nación, sin embargo, la experiencia cotidiana como la de Barrio Sur, demostró que la realidad no correspondía con dicho reconocimiento.

En ese contexto, interesa destacar la necesidad de redefinir los derechos sociales en la trama actual para interpretar la importancia y significado que adquiere la ciudadanía social en espacios de exclusión como el caso del Barrio Sur por lo que cabe repetir que los derechos sociales son derechos humanos exigibles de igual naturaleza, jerarquía e importancia que los derechos políticos y civiles.

Un fenómeno que tocó a las puertas de la democracia para atemorizarla fue la tendencia incremental de la desciudadanización, cuyo proceso se inició con la acelerada pauperización y reducción de derechos en sentido material, pese al formal de reconocimiento de los mismos. Los sujetos sin derechos no son una nueva categoría snob, sino que fueron el producto de las políticas discriminatorias que los gobiernos impulsaron para negar las conquistas laborales, negar los requerimientos básicos para la supervivencia y nulificar todo aquello que fuera público y estatal, convirtiéndolo en privado, exclusivo y alejado de la intervención del Estado.

La desciudadanización, es el proceso por el cual los ciudadanos, en especial los excluidos, pierden la confianza de sus capacidades y reclamos, se arrojan a la mendicidad y pierden la confianza en las instituciones democráticas, económicas e impartidoras de justicia. 


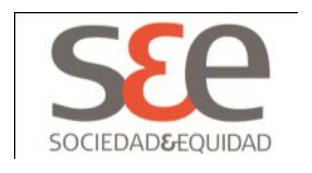

A través de la desciudadanización podemos analizar el proceso reciente y creciente de exclusión de una gran parte de la población de sus derechos sociales. Pérdida de empleo y escasa o nula expectativa de llegar a obtener un trabajo estable con cobertura social: pérdida de la vivienda; dificultades para el acceso a la salud y deterioro de la calidad de la enseñanza; pobreza extrema que afectó sobre todo a los niños, niñas y sus madres, disminución de las condiciones mínimas de igualdad, en el sentido del acceso a bienes sociales esenciales en una sociedad moderna y democrática como es la educación, la salud, el trabajo, la vivienda y la protección a la vejez. En consecuencia, la vulnerabilidad de todos esos derechos civiles, políticos y sociales nos acercó a la plataforma de la desciudadanización ya mencionada.

Las personas entrevistadas en muchos casos no se sienten pobres porque como ellos mismos lo dijeron:

“...hay quienes tienen menos que nosotros y ellos son pobres..."

Medir la pobreza como fenómeno multidimensional es complejo y requiere de un abordaje integral e interdisciplinario. Según el lente con que se mire la realidad, la percepción de la misma será diferente. En este sentido, quedó claramente expuesto que no fue la misma experiencia y vivencia de quienes vivían en el Barrio Sur de quienes pueden vivir en zonas urbanas planificadas donde el acceso a los bienes y servicios, así como la calidad y cantidad de los mismos es incomparable. La vida en los diferentes "Barrios Sur", de Argentina y del mundo es una vida de privaciones y carencias materiales y simbólicas que muchas veces impiden que las personas que allí viven y desarrollan sus actividades puedan considerarse así mismos sujetos de derechos y ciudadanos activos.

Ya mencionamos que el derecho a una vida digna significa mucho más que evitar la privación arbitraria de la vida como en el caso de homicidio:

“... una persona que en su infancia vive, como en tantos países de América Latina, en la humillación de la miseria, sin la menor condición siquiera de crear su proyecto de vida, experimenta un estado de padecimiento equivalente a una muerte espiritual; la muerte física que a ésta sigue, en tales circunstancias, es la culminación de la destrucción total del ser humano..."10

\footnotetext{
10 Sentencia de la Corte Interamericana de Derechos Humanos, caso "Villagrán Morales contra Guatemala", Votos razonados Jueces CançadoTrindade y Abreu Burelli, 1999.
} 


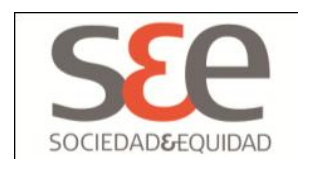

La desciudadanización, vista así, es un fenómeno político que se ve acrecentado y para constatarlo solo es necesario observar las periferias urbanas y sus estrategias de sobrevivencia. Esta situación nos condujo a plantear la existencia de una democracia formal, procedimental, en tanto la democracia solo se afirma en su dimensión institucional y por lo tanto, es difícil comprender:

“Las brechas entre el enfoque de derechos, la proliferación normativa, la robustez de los tratados internacionales de DDHH por un lado y, por otro, las reiteradas omisiones por parte de los estados fundamentalmente en América Latina y en particular en la Argentina, o las argumentaciones basadas en restricciones presupuestarias para sostener condiciones de ilegalidad que implican la vulneración de derechos sociales”"11 (Arcidiácono, 2010, 133).

En este sentido, si bien reflexionamos que las normas son la base de una sociedad democrática, de nada vale el establecimiento de medidas y regulaciones de carácter internacional, nacional o provincial, si dichas medidas excluyen en el ejercicio práctico de los derechos a determinadas personas o grupos porque no se ha considerado sus características particulares.

En igual sintonía, recientemente, la Corte Suprema de Justicia de la Nación, en un fallo sobre el derecho a una vivienda digna, estableció: "Que la primera característica de esos derechos y deberes (DESC) es que no son meras declaraciones, sino normas jurídicas operativas con vocación de efectividad. Esta Corte en reiteradas oportunidades ha sostenido que la Constitución Nacional, en cuanto norma jurídica, reconoce derechos humanos para que estos resulten efectivos y no ilusorios, pues el llamado a reglamentarlos no puede obrar con otra finalidad que no sea la de darles todo el contenido que aquélla les asigne; precisamente por ello, toda norma que debe garantizar el pleno goce y ejercicio de los derechos reconocidos por esta Constitución y por los tratados internacionales vigentes sobre derechos humanos y garantizar, significa mucho más que abstenerse sencillamente de adoptar medidas que pudieran tener repercusiones negativas, según indicó en su Observación General $n^{\circ} 5$ el Comité de Derechos Económicos, Sociales y Culturales, como el intérprete autorizado del Pacto homónimo en el plano internacional y cuya interpretación debe ser tenida en cuenta ya que comprende las condiciones de vigencia de este instrumento que

11 Pautassi, Laura (Organizadora), (2010) Perspectiva de derechos, políticas públicas e inclusión social. Debates actuales en la Argentina, Buenos Aires, Editorial Biblos. 


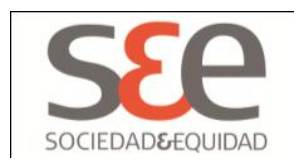

posee jerarquía constitucional en los términos del art. 75, inc. 22, de la Constitución Nacional" 12 .

La cita anterior, aunque extensa, es relevante para fortalecer el análisis teórico y práctico que sostenemos a lo largo del trabajo, en la lógica que afirmó que los Estados al diseñar e implementar políticas públicas están obligados, por normas jurídicas que reconocen derechos humanos. Por lo tanto, limitarse a asegurar mínimos de cada derecho equivale a realizar y aplicar una interpretación restrictiva de las reglas internacionales y nacionales, además de vaciar de contenido a dicha normativa que en nuestro país tiene jerarquía constitucional.

Es así que, más que un conjunto de beneficios, el desafío de la ciudadanía es construir un sentido de pertenencia a una esfera pública para que ciudadanía social, política y civil constituyan un todo donde el Estado cumpla con su obligación de garantizar los derechos sociales, los derechos políticos y los derechos civiles.

La evidencia de las entrevistas sugirió que el problema estaba basado en la falta de acceso a alimentos de calidad y cantidad suficientes conforme los estándares establecidos para garantizar el derecho a la alimentación. Por eso, como señalamos precedentemente, el hambre no está ligado solamente a la disponibilidad, sino al precio de los alimentos, al poder adquisitivo y a las condiciones ocupacionales de las personas. Algunos problemas de salud afines con la alimentación estaban en estrecha relación con la inequidad en el acceso de los alimentos. Esta constatación ya fue reseñada por Miguel Teubal (1989) cuando señaló que la alimentación en Argentina era un problema complejo y multidimensional, por tratarse de un problema de acceso a la alimentación y de insuficiencia de capacidad de compra para adquirir los alimentos por parte de ciertos sectores sociales, como un problema socioeconómico y político. En consecuencia, advertimos la vigencia hasta el presente del planteo que autores clásicos como De Castro (1948), Sen (1982), Teubal (1989), Aguirre (2005), entro otros ya reconocían el problema estructural de la insuficiencia o falta de acceso a alimentos de calidad y nutritivos conforme los requerimientos del cuerpo humano y según la etapa de desarrollo y crecimiento del mismo.

\footnotetext{
12 Fallo de la Corte Suprema de Justicia de la Nación, Q. 64. XLVI. RECURSO DE HECHO Q. C., S. Y. c/ Gobierno de la Ciudad de Buenos Aires s/ amparo, Abril de 2012.
} 


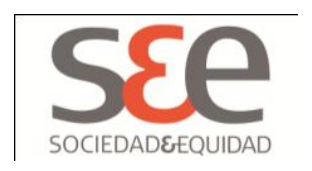

\section{Conclusiones}

Para trabajar el derecho a una alimentación adecuada como derecho humano perteneciente al grupo de los derechos económicos, sociales y culturales fue necesario partir de la nueva concepción que reconoció la efectivización de los mismos como derechos plenos. En este sentido, aunque entendemos que las leyes son la base de una sociedad democrática, consideramos que -no obstante- pueden resultar ineficaces e insuficientes si la puesta en ejecución de las mismas no son acompañadas por políticas públicas efectivas que respondan a los estándares internacionales de derechos humanos y conviertan a las personas a quienes se dirigen en auténticos titulares de derechos exigibles.

En otras palabras, de nada vale el establecimiento de medidas y regulaciones de carácter internacional, nacional o provincial si dichas medidas exceptuaron en el ejercicio de los derechos a determinadas personas o grupos por considerarlos meros receptores de beneficencia y no sujetos con derechos exigibles.

En consecuencia, esta investigación puso en evidencia, por un lado, las fisuras existentes entre el reconocimiento del enfoque de derechos con la incorporación de los tratados internacionales de DDHH y por el otro lado, las fracturas producidas por las omisiones y faltas del Estado en la observancia de sus obligaciones como consecuencia de la ausencia de una política pública coordinada entre los diferentes niveles de gobierno responsables de llevar adelante estas políticas y articulada con la sociedad civil involucrada en la problemática relativa a esta cuestión.

Consideramos también que el problema de la efectivización del derecho a una alimentación adecuada es más complejo que el cálculo de los ingresos y los costos de un conjunto de alimentos porque también envuelve las relaciones sociales, los diferentes territorios así como las políticas y sus regulaciones. Que una política pública reconozca el derecho humano a la alimentación, no implica la modificación repentina en la forma de pensarla ni de diseñarla por parte de los creadores, implementadores y administradores en los diferentes niveles: federal y local. La declaración no convierte instantáneamente a sus beneficiarios en sujetos de derechos, porque la lógica que primó fue la de considerar a las personas como objetos de beneficencia. Queda claro que el asunto es complicado y por lo tanto, es necesario hacer un esfuerzo que posibilite entender el ejercicio de los derechos dentro del paraguas de los derechos humanos reconocidos en la normativa interna.

Para que una política sea sustentable demanda de la formación y organización de un conjunto de especialistas del ámbito público y de organismos 


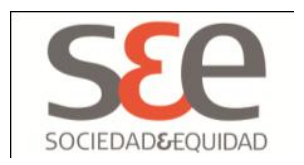

no gubernamentales como brazos de extensión para llegar a los lugares donde el Estado no pudo hacerlo; este es el caso de las áreas de salud pública y educación, porque la enseñanza alimentaria es transversal a toda estrategia que se emprenda. Concientización a la población en higiene, ingestión saludable de alimentos, forma de preparación de los mismos, relación directa de la dieta con la edad y etapa de crecimiento de cada persona son los pilares para una vida sana.

Una dieta sana debe incluir la cantidad suficiente de energía, hidratos de carbono, proteínas, grasas y micronutrientes para cada etapa de la vida y para cada fase biológica. Pero esto no es todo; debe contener alimentos de todos los grupos y debe combinarlos de manera adecuada. A saber, cereales y tubérculos, productos de origen animal, lácteos y sus derivados, frutas, verduras y grasas. El agua no se considera un alimento como tal, pero su inclusión en la dieta es imprescindible y debe ser en cantidad importante. Sin embargo, ocurre con frecuencia en los programas alimentarios que no se cubren los requerimientos para algunos macro o micronutrientes o que, en ocasiones, hay una sobre representación de alguno de ellos. Es común, asimismo, que los programas no tomen en cuenta las particularidades de la cultura alimentaria de las poblaciones a las que van dirigidos, razón por la cual su éxito podría verse mermada.

De lo expresado, se desprende que es preciso impulsar políticas públicas en el área de alimentación con la participación ciudadana como herramienta porque facilita el intercambio de ideas y opiniones sobre la problemática que afecta a la sociedad. Asimismo, este instrumento demanda responsabilidad porque exige sentirse partícipe y tener conocimiento para controlar y demandar transparencia en los actos de quienes elegimos a través de nuestro voto.

La calidad democrática de cada país puede valorarse a través de la definición, elaboración y evaluación de sus políticas públicas. En este contexto, la gestión participativa es una acción forjada desde la sociedad civil, que busca producir cambios de adentro hacia fuera y cuyos resultados impactarán en toda la sociedad.

Cabe concluir que con este artículo quisimos llamar la atención de los diferentes operadores y efectores del derecho a una alimentación adecuada. En otros términos, trabajamos con el compromiso de la academia al servicio de la comunidad, acentuando la importancia que implicó la incorporación de los tratados con jerarquía constitucional a nuestra Constitución Nacional y Provincial, sin desconocer que dicha afiliación per se no objetiva el derecho a una alimentación adecuada, por dicha razón, este estudio quiso dar voz a los sujetos de derechos y, al hacerlo, identificó y construyó nuevas formas, más humanas pero 


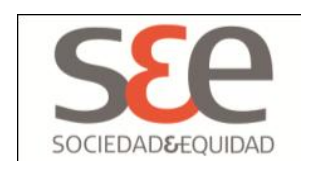

académicamente rigurosas, para pensar el tema de los derechos, su exigibilidad y justiciabilidad al servicio de la ciudadanía en su conjunto. No obstante, a modo de conclusión señalamos que las políticas públicas y las estrategias de desarrollo deben tener como fundamento los principios y estándares de los derechos humanos.

El derecho a la alimentación no se agota en una cantidad de calorías y nutrientes, en sentido amplio comprende la posibilidad de tener acceso físico y económico a los alimentos $\mathrm{y} / \mathrm{o}$ a los medios para producirlos. El derecho a la alimentación implica, asimismo, tener la garantía de que los alimentos sean adecuados para las distintas etapas de crecimiento y desarrollo de las personas. Ejercer este derecho pasa también por el respeto a las pautas culturales de cada región y grupo, por encima de la lógica de poder que determina quién y qué come y quién no.

Cabe concluir que con esta investigación, nuestra finalidad fue propagar el debate y las discusiones ya planteadas desde hace tiempo, pero ahora desde una lectura crítica en torno a la realidad social. Creemos que la interpretación y el análisis, lejos de cerrarse, están abiertos porque desde el momento en que naturalizamos la diferencia, la pobreza, el abandono, la violencia y la exclusión estamos condenados a reproducir estas prácticas una y otra vez, porque aunque cambie el reconocimiento de beneficiarios a titulares de derechos, el reconocimiento discursivo no alcanza.

\section{Referencias bibliograficas}

Abramovay Ricardo (1991). O que é Fome. Brasil: Editorial Brasilense.

Abramovich Víctor y Courtis Christian (2006). El umbral de la ciudadanía. Buenos Aires: Del Puerto.

Abramovich Víctor y Courtis Christian (2001). Los derechos sociales como derechos exigibles, Madrid: Trotta.

Abramovich Víctor y Pautassi Laura (2009). "El enfoque de los derechos y la institucionalidad de las políticas sociales", en La revisión judicial de las políticas sociales. Estudio de casos, Buenos Aires, Editores del Puerto.

Abramovich Víctor (2006). "Una aproximación al enfoque de derechos en las estrategias y políticas de desarrollo”, en Revista CEPAL N88, Santiago de Chile. 


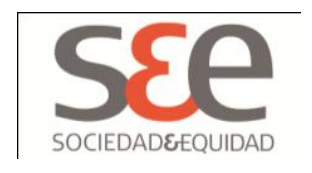

Abramovich Victor, Courtis Christian (2006). Hacia la exigibilidad de los derechos económicos, sociales y culturales. Estándares internacionales y criterios de aplicación ante los tribunales locales, Buenos Aires: Editores Del Puerto.

Abregú Martín, Courtis, Christian (comp.) (2004). La aplicación de los tratados Sobre derechos humanos por los tribunales locales, Buenos Aires: Editores del Puerto.

Aguilar Villanueva, Luis (1992). La hechura de las Políticas, México: Porrúa.

Aguirre Patricia (2005). Estrategias de consumo: qué comen los argentinos que comen, Buenos Aires: Ciepp Miño y Dávila.

Aguirre Patricia (2010). Ricos Flacos y gordos pobres. La alimentación en crisis, Buenos Aires: Capital Intelectual.

Alegre Marcelo y Gargarella Roberto (coordinadores) (2007). El derecho a la igualdad. Aportes para un constitucionalismo igualitario, Buenos Aires: LexisNexis.

Alfaro Griselda (2008). El hambre: una violación a los derechos inherentes a la dignidad humana. La justiciabilidad de los DESC, en Casali de Babot Judith (dir): En búsqueda de una Cultura Política Democrática, Tucumán: Facultad de Filosofía y Letras, UNT.

Cademartoni, Fiorella, Tesis de Grado (2005). "Naturalización de la desigualdad social en las prácticas cotidianas de la comunidad asentada a orillas de la vía. Barrio Alberdi Norte," Facultad de Filosofía y Letras, UNT.

De Castro, Josué (1948). Geografía da Fome: A Fome no Brasil, Río de Janeiro, Brasil, Empresa Gráfica 0 Cruzeiro.

Do Carmo de Freitas María (2002). “Un abordaje fenomenológico del Hambre”, en Revista Nutrición, Campinas, Enero-Abril.

Herkovits Damián (2008). La construcción de la malnutrición infantil: una etnografía sobre las condiciones y posibilidades que contribuyen a su reproducción en hogares pobres de la Ciudad de Buenos Aires, Buenos Aires: CEDES, FLACSO.

Mansilla Sandra (1993). Del Conventillo a la Villa de Emergencia. Segregación Residencial y Migraciones Interurbanas en San Miguel de Tucumán, en Revista Geográfica No 118 Julio-Diciembre, Brasil: Instituto Panamericano de Geografía e Historia. 


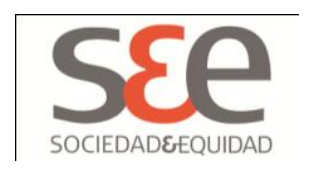

Teubal Miguel (1989). “Hambre y Alimentación en Argentina”, en Revista Realidad Económica, № 89, Buenos Aires: IADE.

O’ Donnell Guillermo (1993). “Estado, democratización y Ciudadanía”, en Revista Nueva Sociedad, № 128.

Pautassi Laura (Organizadora) (2010). Perspectiva de derechos, políticas públicas e inclusión social: debates actuales en la Argentina, Buenos Aires: Editorial Biblos.

Reta Magdalena, Rossi Graciela y Toler Stella Maris (2008). "La evaluación de las políticas alimentarias. Consideraciones metodológicas a partir del caso de la Ciudad de Concordia", Concordia: UNER.

Raimundo Sousa Ribeiro Junior José (2008). Tesis inédita para el Título de Grado en Maestro de Geografía: "Alimentación y una crítica de la vida cotidiana a partir de la Geografía Urbana," Facultad de Filosofía, Letras y Ciencias Humanas, Brasil: Universidad de San Pablo.

Samaja Juan (2000). Muestras y representatividad en vigilancia epidemiológica mediante sitios centinelas." Material bibliográfico para cursos de postgrado en Metodología de la investigación Científica. Inédito.

Sen Amartya (1982). Poverty and Famines: an essay of entitlement and deprivation, Oxford, Claredon Press.

Vasilachis de Gialdino Irene (2006). Estrategias de investigación cualitativa, Barcelona, Gedisa. 


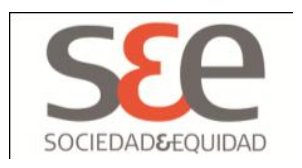

\section{Anexo Fotográfico Barrio Sur}
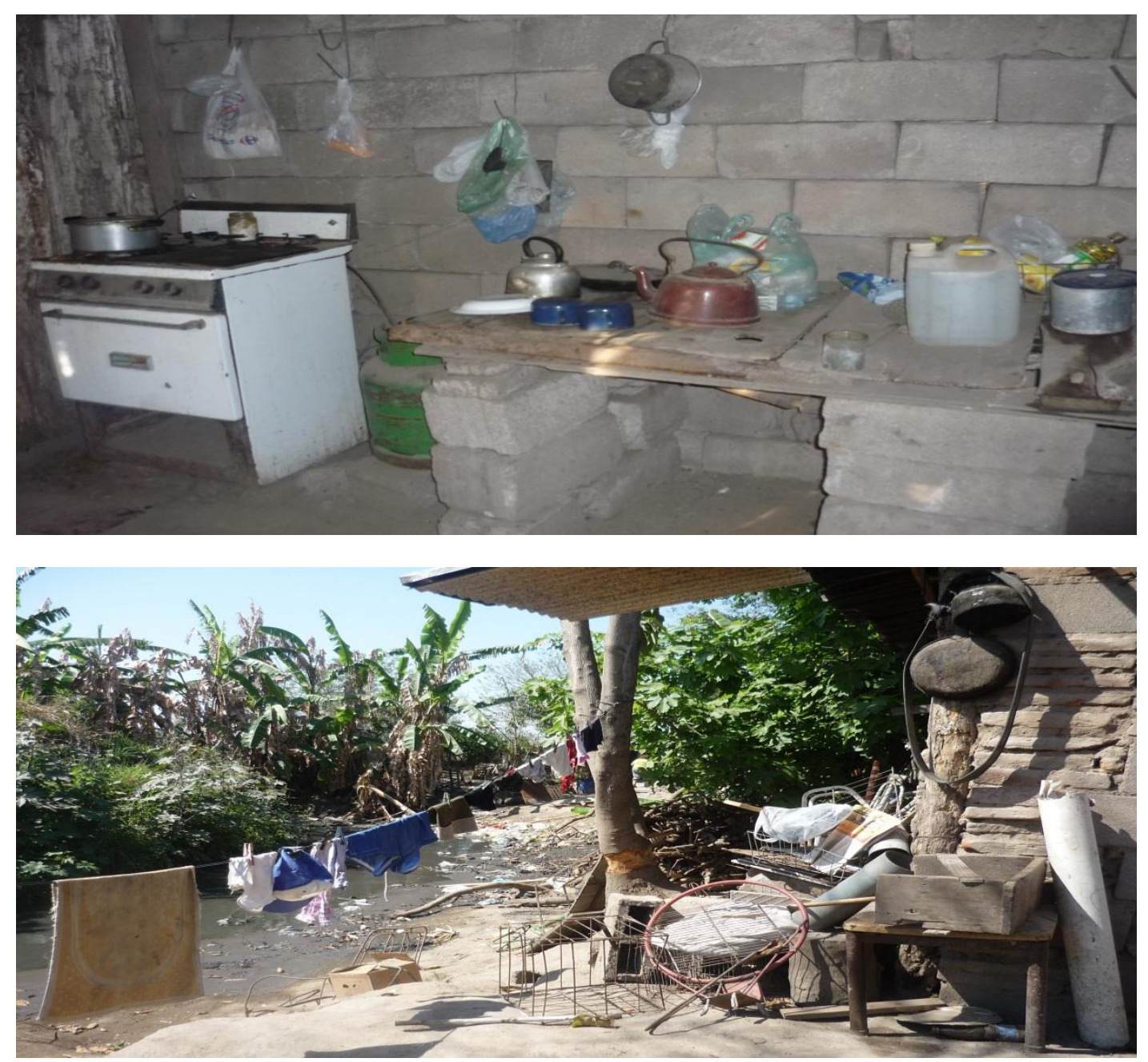
Rev. Sociedad \& Equidad № 5, Enero de 2013. Pp 213-237
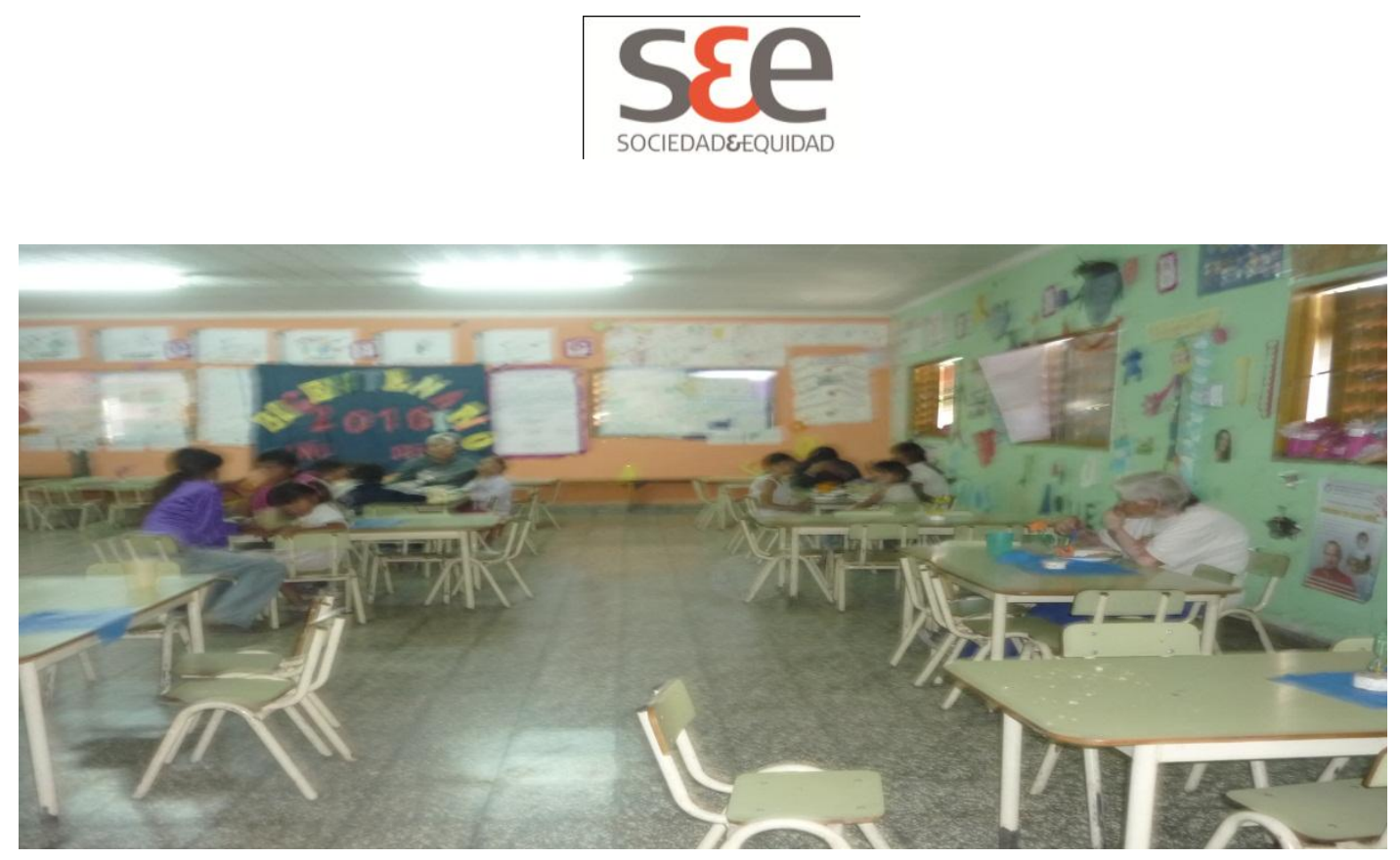